\title{
Liquid Nitrogen
}

National Cancer Institute

\section{Source}

National Cancer Institute. Liquid Nitrogen. NCl Thesaurus. Code C68796.

Nitrogen in a liquid state, having been super-cooled to about -200 degrees Celsius. 